\title{
A Comparative Study on Satisfaction with Current Standard of Living and its Effects on Overall Life Satisfaction: Case of Romania, V4 and EU-15
}

\author{
DOI: 10.12776/QIP.V22I1.1047
}

\author{
Vincent Šoltés, Bibiána Nováková, Zsuzsanna K. Szabo
}

Received: 12 December 2017 Accepted: 13 February 2018 Published: 31 March 2018

\begin{abstract}
Purpose: The main aim of the paper is to explore the patterns of differences in overall life satisfaction in Romania and the V4 in comparison to the EU-15.
\end{abstract}

Methodology/Approach: We carried out contingence analysis and linear regression analysis in order to assess the impact of income and satisfaction with current standard of living on overall life satisfaction.

Findings: The main novelty of our research, which presents a significant contribution to the body of knowledge, is that we found that life satisfaction of citizens increases with income category, but there is a more relevant relationship between subjective life satisfaction and subjective self-reported satisfaction.

Research Limitation/implication: Despite several limitations of our research (data from the third wave of EQOLS, restricted number of determinants of life satisfaction, absence of effects of financial crisis), we can say that material living conditions and satisfaction with current standard of living still play an important role in life satisfaction of the citizens and the well-being of nations.

Originality/Value of paper: The paper focuses on the importance of material living conditions and satisfaction with current standard of living in overall life satisfaction to explore the patterns of differences of life satisfaction in selected countries, and that results are useful for policymakers.

Category: Research paper

Keywords: satisfaction; income; standard of living; quality of life; Romania; Visegrad Group countries 


\section{INTRODUCTION}

Quality of life (QOL) represents a complex, multi-dimensional and interdisciplinary concept, for which no uniform, universally accepted definition exists (Apparicio, Seguin and Naud, 2008; Das, 2008; Royuela, Moreno and Vayá, 2009; Ulengin, Ulengin and Guvenc, 2001).

According to Fayers and Machin (2013), QOL reflects the difference between the hopes and expectations of the individual and of the individual's present experience.

In the process of QOL assessment, the important parts are the precise definition of the explored area and the appropriate selection of suitable indicators (Murgaš, 2009; Řepková and Stavárek, 2014; Gavurová, 2012).

QOL stands for a broader concept than economics, industry and living conditions. It includes a number of factors affecting our evaluation of life above its material page. In Report of the commission on the measurement of economic performance at social progress (Stiglitz, Sen and Fitoussi, 2009), there is a distinction between three approaches of QOL measuring. The first approach is closely connected to psychological research and focuses on the subjective evaluation of well-being. The second approach considers human life in terms of various deeds and beings and individual freedom to choose between these individual abilities. The third approach was developed in the context of the economic tradition and has its basis on fair allocation.

Besides the term QOL, there are various interrelated terms that are often used as synonyms, although their meaning is not yet precisely defined, e.g. life satisfaction, happiness, subjective well-being, well-being etc. According to Diener (2005), subjective well-being represents all of the various types of evaluations, both positive and negative, that people make of their lives. Life satisfaction is a respondent's evaluation of his/her life taken as a whole. On the other hand, domain satisfactions are judgments of people made by evaluating major life domains such as living standard, health, job, leisure time, social relationships and family. Veenhoven (1996) describes happiness as a person's overall evaluation of his life as a whole. Deaton (2008) distinguishes between terms of life satisfaction and happiness.

Respondents are asked questions about life satisfaction in order to give them the chance to make an overall evaluation of their lives. The results are often interpreted as measures of happiness, but happiness can also be thought of as relating to affect, and can be measured from experiential questions (e.g. about smiling a lot or feeling happy or absence of depression, often during the day before the interview).

QOL has been investigated from different aspects that imply its multidimensional character (e.g. Khaef and Zebardast, 2016; Eby, Kitchen and Williams, 2012). In Eurostat report (2011) a development of multidimensional indicators is recommended. 


\section{LITERATURE REVIEW}

The importance of different life circumstances in shaping the overall satisfaction of life has been the subject of different research studies. Economists are interested in the role of income as a gain to the individual life satisfaction. Evidence in time series data for developed countries, transition countries, and less developed countries confirms that short term fluctuations in happiness and income are positively associated but long term trends in happiness and income are not related (Easterlin, 2013). These results suggest only little or no long-term interrelation between national income and people's average level of life satisfaction. Another research study in the USA and UK has confirmed a small impact of income on life satisfaction in relation to other life circumstances such as age, sex or racial group (Blanchflower and Oswald, 2004). Further, a correlation between country average levels of life satisfaction and the Gini coefficient, the most common measure of income inequality, (Eurofound, 2015) was not confirmed.

On the other hand, Deaton (2008) considers income and health as the most important factors which enable people to lead a good life. He also claims that health alone does little to enable people to lead a good life. Other factors (e.g. education or participation in society) are also important determinants, but evaluations of income and health incline to get primary attention in most assessment of human well-being. Some research studies prove the fact that the higher the level of economic development and wealth of a country, the weaker its impact on reported satisfaction (e.g. Frey and Stutzer, 2001; Veenhoven, 2005).

Another research in this area identifies that people in wealthier countries are more satisfied with their material conditions or with life as a whole and this life satisfaction is more significantly affected also by other objective conditions in poor countries (Schyns, 2002). Based on Zagórski, Kelley and Evans (2011), poor people are usually more satisfied in wealthy societies than they are in poor societies, and consequently wealthy people are happier in poor societies than in rich societies. These relations pertain to material conditions, as well as other domains, such as education, health or job. Another important aspect when talking about satisfaction with life and satisfaction with material living conditions is the process of modernization and post-modernization (Inglehart, 1997; Inglehart and Welzel, 2005). Inglehart's theory is based on the diminishing impact of material living conditions on life satisfaction at higher levels of human and social development. In post-modern societies, changes of value system have been observed. Needs of a higher order concerning self-realization and self-expression have become more important for individuals and society. Because of the fact that in the most developed societies, material needs are more regularly satisfied, the satisfaction of these needs and further accumulation of material goods do not increase the feeling of happiness and other needs become more important. In other words, for wealthy people satisfaction with basic material needs is less important than that of poor people. Consequently, the same increase in material standard of living satisfies the poor more than the wealthy. 
Wiese (2014) tested the impact and the importance of GDP on the well-being of citizens in the European countries. He found important differences in connection with life satisfaction and the deviation from trend growth among certain countries (Spain, Italy, Portugal and Greece) and confirmed that some characteristics of their welfare state might determine their citizens to be more dependent on certain economic variables such as rising income.

Zagórski (2011) examined the relations between income and happiness change in Poland in a way that is consistent with Inglehart's modernization theory. He also assessed the impact of income and modernization on satisfaction with income and life as a whole by regression equations. Various research studies investigated the relationship between income and life satisfaction (Cummins, 1998; Diener and Fujita, 1995; Deaton, 2008; Havasi, 2013).

\section{DATA AND RESEARCH METHODOLOGY}

We ran our analysis on data from Eurofound database (Eurofound, 2015) which includes data obtained from the third wave of QOL surveys in the EU (European Quality of Life Surveys - EQOLS, 2012). Data were collected individually for each citizen who replied to the questionnaire, available through the UK Data Service, and for each country available on interactive database on the website of Eurofound. Concretely, we used data about satisfaction with different areas of life (education, current standard of living, accommodation, family life, health, social life, economic situation in country and overall life satisfaction) and data about household income in EUR. Households were divided into 22 income categories from the lowest monthly income (less than 50 EUR) to the highest monthly income (5.500 EUR and more). Questions from European Quality of Life Surveys (EQOLS) conducted in 2012 were put to people about their subjective perception of satisfaction with life as a whole and also satisfaction with partial areas of life (e.g. health, present standard of living). People in the Eurofound questionnaire evaluated their satisfaction with life and with partial life areas in the scale from 1 to 10 , which refers from "I am very dissatisfied to I am very satisfied".

We used the contingence analysis as a method to find satisfaction patterns with current standard of living and income among citizens in the context of overall life satisfaction. Influence of different satisfaction elements on overall life satisfaction in Romania, the V4 and the EU-15 countries was tested by the means of multiple linear regression analysis conducted in statistical software R. A similar approach to linear regression models was used in various studies (e.g. Deaton, 2008; Saksonova and Vilerts, 2015; Havasi, 2013; Drule, et al., 2014). 
Our linear regression model was estimated as a QLS regression by means of the next formula:

$$
Y=\beta_{0}+\beta_{1} X_{1}+\ldots \beta_{n} X_{n}+\varepsilon
$$

where $Y$ is the dependent variable - overall satisfaction with life, defined on the scale from 1 to 10 , which refers from very dissatisfied to very satisfied; $\beta_{0}$ is the intercept term; $X_{i}$ is a vector which consists of various variables that affect satisfaction with life, partial satisfaction with different life domains defined on the scale from 1 to $10 ; \beta_{n}$ are the $\mathrm{n}$ coefficients for independent variables, the vector of coefficients shows the impact of the previously mentioned variables on overall life satisfaction; $\varepsilon$ is the error term.

Estimation was done in both the classic and the standardized versions. Standardized regression enables us to order the factorial variables in accordance with their impact on each variable on the dependent variable.

\section{RESULTS AND DISCUSSIONS}

Modernisation of Romania and the V4 and the consequential improvement in material conditions influence the relations between material living conditions and satisfaction with them and with life in general. At the beginning, we focused on connections between the level of material living conditions and the overall life satisfaction within countries and also between countries. Our calculations confirmed that richer people are more satisfied with life and also people of richer nations are more satisfied too.

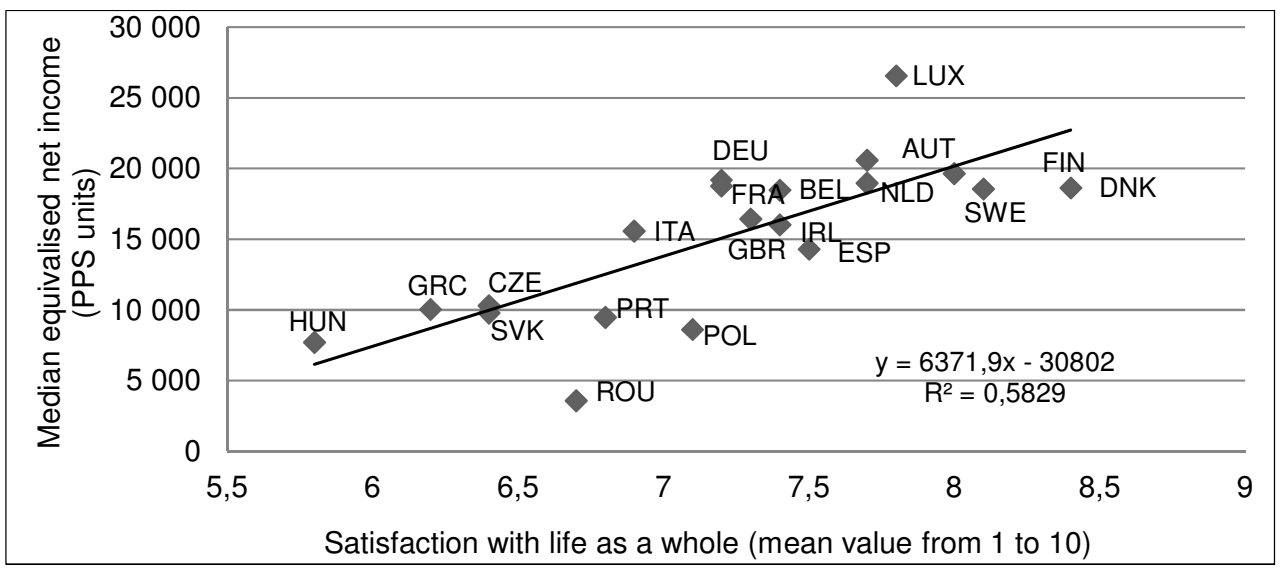

Notes: 3 Letter ISO Codes: Austria-AUT, Belgium-BEL, Czech Republic-CZE, Denmark-DNK, Finland-FIN, France-FRA, Germany-DEU, Greece-GRC, Hungary-HUN, Ireland-IRL, Italy-ITA, Luxembourg-LUX, Netherlands-NLD, Poland-POL, Portugal-PRT, Romania-ROU, Slovakia-SVK, Spain-ESP, Sweden-SWE, United Kingdom-GBR, PPS-purchasing power standard units.

Figure 1 - Relationship Between Median Equivalised Net Income and Satisfaction with Life as a Whole In Romania, the V4 and the EU-15 Countries (2012) 
Fig. 1 reflects on the relationship between the objective indicator of material living conditions - median equivalised net income measured in PPS (Eurostat, 2015) and subjective life satisfaction expressed in mean value (scale from 1 to 10). As we can see from the graph, mean life satisfaction is higher in countries with higher values of median equivalised net income. Value of correlation coefficient between income and subjective life satisfaction of citizens is 0.763 , which means that there is a strong positive relationship between them and thus confirms our expectations. The EU-15 countries are situated in the top right part of the figure because of higher values of income and life satisfaction, except for Greece and Portugal, which have the lowest level of income out of the EU- 15 . Romania and the V4 countries are situated on the bottom left part of the figure with considerably lower values of income and satisfaction. Poland and Romania are situated below the linear regression curve with higher values of life satisfaction in relation to income. For example, citizens of Romania report similar level of life satisfaction as citizens of Portugal in spite of different levels of income. In other words, people in Romania are more satisfied with life in general according to the level of country's income. With income expressed as a $\log$, the relationship is close to linear and the value of correlation coefficient is 0.707 .

The next graph (Fig. 2) points to the level of overall life satisfaction in households in Romania divided according to their income categories. In each income category we can see percentage of households according to their level of overall life satisfaction on the scale from 1 to 10 . We labelled households which denoted their satisfaction with life on the scale from 1 to 3 as "dissatisfied", from 4 to 6 as "satisfied" and from 7 to 10 as "very satisfied". We analyzed a number of 1,315 households.

We can conclude that the percentage of very satisfied households is rising closely connected to the income category. On the other hand, the percentage of satisfied people is relatively high also in the lowest income category. We can consider the fact that overall life satisfaction of people in Romania is shaped also by other dimensions of life, though income plays an important role. 


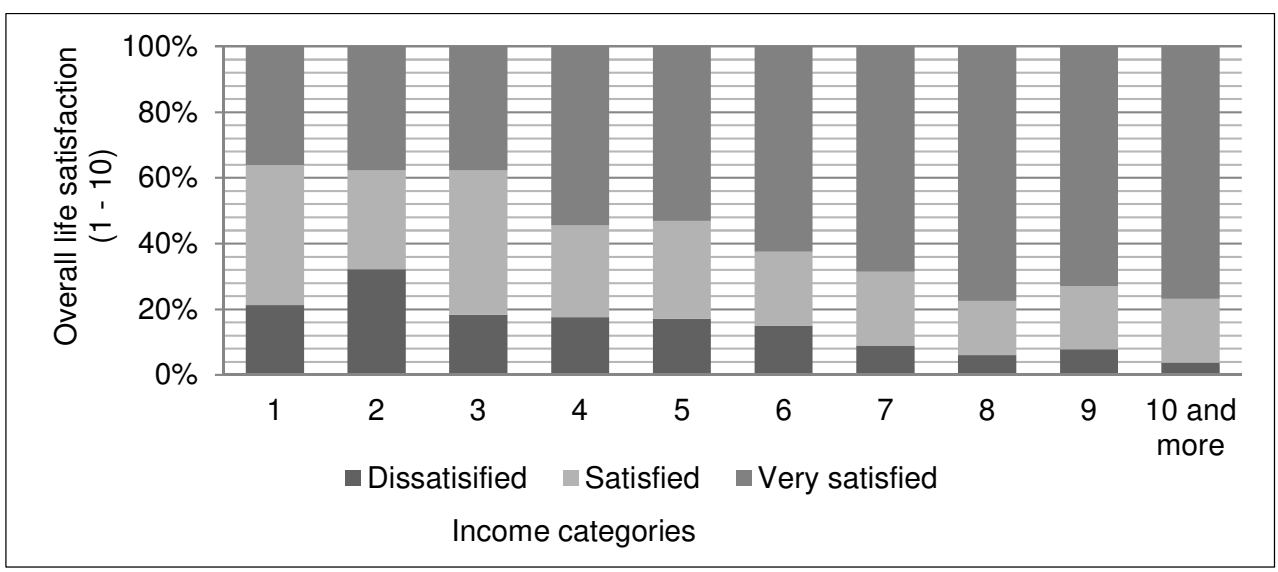

Notes: Income categories (monthly income): 1 - Less than $€ 50 ; 2-€ 50$ to $€ 99 ; 3-€ 100$ to $€ 149$; 4- $€ 150$ to $€ 199$; 5- $€ 200$ to $€ 249$; 6- $€ 250$ to $€ 349$, 7- $€ 350$ to $€ 449$; 8- $€ 450$ to $€ 599$; 9 - $€ 600$ to $€ 749$; $10-€ 750$ to $€ 899 ; 11-€ 900$ to $€ 1.124 ; 12-€ 1.125$ to $€ 1.349 ; 13-€ 1.350$ to $€ 1.649$; $14-€ 1.650$ to $€ 1.949$; $15-€ 1.950$ to $€ 2.249$; $16-€ 2.250$ to $€ 2.699$; $17-€ 2.700$ to $€ 3.149$; $18-€ 3.150$ to $€ 3.599$; 19 $€ 3.600$ to $€ 4.049 ; 20$ - $€ 4.050$ to $€ 4.499 ; 21-€ 4.500$ to $€ 5.499 ; 22-€ 5.500$ or more.

Figure 2 -Percentage of People Who Are Satisfied with Their Life as a Whole Within Income Categories in Romania (2012) (Source: Calculations of the Authors Based on Data from Eurofound)

Next, we compared the results of contingence analysis between Romania, the V4 and the EU-15 to explore relations and differences between income categories, categories of self-reported satisfaction with current standard of living and overall life satisfaction within countries in more detail.

Table 1 - Percentage of People Who Are Satisfied with Their Lives as a Whole (7-10) within Income Categories (Source: Calculations of the Authors)

\begin{tabular}{|l|c|c|c|c|c|c|c|}
\hline & \multicolumn{1}{|l}{ Very Poor } \\
\hline & $\mathbf{1 - 3}$ & $\mathbf{4 - 6}$ & $\mathbf{7 - 9}$ & $\mathbf{1 0 - 1 2}$ & $\mathbf{1 3 - 1 5}$ & $\mathbf{1 6 - 1 8}$ & $\mathbf{1 9 - 2 2}$ \\
\hline Romania & 37.3 & 56.6 & 73.0 & 80.5 & 75.6 & 75.0 & 100.0 \\
\hline V4 & 51.2 & 41.0 & 47.7 & 64.5 & 72.1 & 86.9 & 65.0 \\
\hline EU-15 & 63.0 & 55.6 & 51.5 & 63.7 & 74.2 & 82.1 & 89.3 \\
\hline
\end{tabular}

We can experience that the percentage of people who scored their satisfaction with life as a whole on the 10-point satisfaction scale from 6 to10 (very satisfied) within income categories increases, but not in all categories (see Tab. 1). Differences exist between countries mainly due to income distribution. In Romania the most people belong to the first twelfth income categories in which we can see trend of growth of very satisfied people, but with a diminishing pace. On the other hand, the V4 countries confirm the growth trend from the sixth category and the EU-15 from the seventh category. When we consider relationship between self-reported satisfaction with current standard of living and 
overall life satisfaction (Tab. 2), percentage of very satisfied people increases almost within all satisfaction categories. It was also confirmed that there is a more obvious relationship between subjective life satisfaction and subjective self-reported satisfaction with current standard of living than between subjective life satisfaction and income itself. This finding corresponds with results of Havasi (2013).

Table 2 - Percentage of People Who Are Satisfied with Their Lives as a Whole (7-10) within the Categories of Self-Reported Satisfaction with Present Standard of Living (Source: Calculations of the Authors)

\begin{tabular}{|l|c|c|c|c|c|c|c|c|c|c|}
\hline \multicolumn{10}{|c|}{ Very Dissatisfied } & \multicolumn{10}{|c|}{ Very Satisfied } \\
\hline Romania & 11 & 20 & 21 & 31 & 36 & 50 & 77 & 89 & 88 & 87 \\
\hline V4 & 16 & 19 & 20 & 32 & 39 & 51 & 75 & 82 & 90 & 88 \\
\hline EU-15 & 19 & 20 & 27 & 31 & 46 & 58 & 78 & 88 & 93 & 92 \\
\hline
\end{tabular}

Then, we explored the importance of self-reported satisfaction with current standard of living in overall life satisfaction, separately for Romania, the V4 and the EU-15. We can quantify contribution of this partial satisfaction to the overall life satisfaction by means of multiple linear regression models in which dependent variable is overall life satisfaction and 7 independent variables are partial satisfactions with various dimensions of life, scored from 1 to 10 . The aim of the econometric models was to identify the significance of the impact of partial satisfaction with different life dimensions on overall life satisfaction.

Firstly, we calculated linear regression model for people in Romania on data from the third wave of EQOLS (2012). Linear model shows the significant influence almost in all life dimensions on overall life satisfaction except for satisfaction with education, accommodation and social life. Values of coefficients can be interpreted as follows, e.g. when satisfaction with current standard of living increases by one unit, measure of life satisfaction will increase by 0.47 units. The highest positive effect on overall life satisfaction based on values of regression coefficients was recognised in satisfaction with current standard of living, followed by family life and health. This finding can confirm our assumptions that satisfaction with current standard of living is the most important factor in determining life satisfaction in Romania.

Table 3 - Multiple Linear Regression Model for Life Satisfaction in Romania (Source: Calculations of the Authors)

\begin{tabular}{|l|r|r|r|r|r|}
\hline \multirow{2}{*}{} & \multicolumn{2}{|c|}{ Coefficients } & Standard Error & \multicolumn{1}{c|}{ t-value } & \multicolumn{1}{c|}{$\operatorname{Pr}(>|\mathbf{t}|)$} \\
\cline { 2 - 4 } & Classic & \multicolumn{1}{|c|}{ Standardized } & & & \\
\hline Intercept & 1.32203 & - & 0.25560 & 5.172 & $<0.001 * * *$ \\
\hline Education & 0.02065 & 0.01625552 & 0.02787 & 0.741 & 0.4587 \\
\hline
\end{tabular}




\begin{tabular}{|l|r|r|r|r|r|}
\hline & \multicolumn{2}{|c|}{ Coefficients } & \multicolumn{1}{c|}{ Standard Error } & t-value & \multirow{2}{*}{$\operatorname{Pr}(>|\mathbf{t}|)$} \\
\cline { 2 - 5 } & \multicolumn{1}{|c|}{ Classic } & \multicolumn{1}{|c|}{ Standardized } & & \\
\hline Current standard of living & 0.47488 & 0.50469037 & 0.02536 & 18.722 & $<0.001 * * *$ \\
\hline Accommodation & -0.02897 & -0.02591020 & 0.02793 & -1.037 & 0.2999 \\
\hline Family life & 0.15848 & 0.14333598 & 0.02780 & 5.700 & $<0.001 * * *$ \\
\hline Health & 0.08763 & 0.09722058 & 0.02173 & 4.032 & $<0.001 * * *$ \\
\hline Social life & 0.03869 & 0.03700074 & 0.02789 & 1.387 & 0.1656 \\
\hline Economic situation & 0.05792 & 0.05285615 & 0.02293 & 2.526 & $0.0116 *$ \\
\hline
\end{tabular}

Significant codes: 0 ‘***’ 0.001 ‘**’ 0.01 '*’ 0.05 '. 0.1 ' ’ 1. Adjusted R-squared: 0.4442 , number of observations $=1445$, F-statistic: 165.9 , p-value: $<0.001$.

Secondly, we calculated linear regression model for people in the V4. Linear model shows the significant influence almost in all life dimensions on overall life satisfaction except for satisfaction with education and accommodation. The highest positive effect on overall life satisfaction based on values of regression coefficients was recognised in satisfaction with present standard of living, followed by family life and economic situation. The influence of partial satisfaction with current standard of living is less significant in comparison to Romania (lower absolute value of coefficient).

Table 4 - Multiple Linear Regression Model for Life Satisfactions in the V4 (Source: Calculations of the Authors)

\begin{tabular}{|l|r|r|r|r|r|}
\hline & \multicolumn{2}{|c|}{ Coefficients } & \multirow{2}{*}{ Standard Error } & t-value & \multirow{2}{*}{$\operatorname{Pr}(>|\mathbf{t}|)$} \\
\cline { 2 - 6 } & \multicolumn{1}{|c|}{ Classic } & \multicolumn{1}{|c|}{ Standardized } & & \\
\hline Intercept & 2.212730 & - & 0.104846 & 21.105 & $<0.001 * * *$ \\
\hline Education & 0.001314 & 0.001505923 & 0.011424 & 0.115 & 0.908 \\
\hline Current standard of living & 0.380034 & 0.412777087 & 0.014685 & 25.878 & $<0.001 * * *$ \\
\hline Accommodation & -0.010211 & -0.010900390 & 0.014165 & -0.721 & 0.471 \\
\hline Family life & 0.108972 & 0.114203311 & 0.014100 & 7.728 & $<0.001 * * *$ \\
\hline Health & 0.063304 & 0.074541347 & 0.011844 & 5.345 & $<0.001 * * *$ \\
\hline Social life & 0.075498 & 0.081306042 & 0.014022 & 5.384 & $<0.001 * * *$ \\
\hline Economic situation & 0.097818 & 0.097325164 & 0.012467 & 7.846 & $<0.001 * * *$ \\
\hline
\end{tabular}

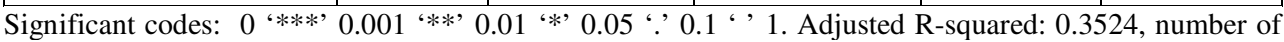
observations $=4964$, F-statistic: 408.9, p-value: $<0.001$. V4: The Czech Republic, Hungary, Poland and Slovakia.

Finally, we compared our results to multiple linear regression model calculated in the EU-15 countries to find differences between Romania, the V4 and the older members of the EU, the 15 more developed countries in Europe. 
Table 5 - Multiple Linear Regression Model for Life Satisfaction in the EU-15 (Source: Calculations of the Authors)

\begin{tabular}{|c|c|c|c|c|c|}
\hline & \multicolumn{2}{|c|}{ Coefficients } & \multirow[t]{2}{*}{ Standard Error } & \multirow[t]{2}{*}{ t-value } & \multirow[t]{2}{*}{$\operatorname{Pr}(>|t|)$} \\
\hline & Classic & Standardized & & & \\
\hline Intercept & 1.466183 & - & 0.059571 & 24.612 & $<0.001 * * *$ \\
\hline Education & 0.004143 & 0.004668565 & 0.005384 & 0.770 & 0.442 \\
\hline Current standard of living & 0.338913 & 0.350259497 & 0.007415 & 45.705 & $<0.001 * * *$ \\
\hline Accommodation & 0.034160 & 0.032559770 & 0.007401 & 4.615 & $<0.001 * * *$ \\
\hline Family life & 0.153671 & 0.146940027 & 0.007174 & 21.421 & $<0.001 * * *$ \\
\hline Health & 0.067434 & 0.074031872 & 0.005803 & 11.621 & $<0.001 * * *$ \\
\hline Social life & 0.149511 & 0.145786011 & 0.007377 & 20.268 & $<0.001 * * *$ \\
\hline Economic situation & 0.066153 & 0.080111672 & 0.004803 & 13.773 & $<0.001 * * *$ \\
\hline
\end{tabular}
observations $=20620$, F-statistic: 1924 , p-value: $<0.001$. EU-15: Austria, Belgium, Denmark, Finland, France, Germany, Greece, Ireland, Italy, Luxembourg, Netherlands, Portugal, Spain, Sweden, United Kingdom.

By examining the results of the EU-15 model, we found the significant influence almost of all life dimensions on overall life satisfaction except for satisfaction with education. Influence of satisfaction with current standard of living on overall life satisfaction is the smallest out of all calculated models (value of coefficient is the lowest). We can state that importance of this partial satisfaction is the weakest for citizens of the EU-15. On the other hand, value of coefficient for satisfaction with social life almost doubled compared to the V4. Linear model shows the positive significant influence of satisfaction with accommodation, in comparison to Romania and the V4 model, where coefficients were not significant.

\section{CONCLUSIONS}

This paper focuses on the importance of material living conditions and satisfaction with current standard of living on overall life satisfaction, in order to explore the patterns of differences of life satisfaction in Romania and the V4 countries in comparison to more developed EU-15 countries.

At the beginning, we explored the positive relationship between the objective indicator of material living conditions (median equivalised net income) and mean subjective life satisfaction. Our calculations confirm that richer people are more satisfied with life and also people of richer nations are more satisfied. It can be stated that despite the diminishing importance of material and living conditions in the value system of post-material societies (Inglehart and Welzel, 2005) they are still important in life satisfaction of the EU citizens. Our results correspond to 
Deaton (2008) who confirmed that the level of national income is an important positive determinant of life satisfaction and the rate of growth of income is a negative determinant for each of the age groups. On the other hand, some research studies argument that there are no or only weak positive relationship between life satisfaction and the level of economic development measured e.g. by GDP per capita or national income (e.g. Eurofound, 2012).

According to the contingence analysis, we found that overall life satisfaction of citizens increases with income category, but there is a more obvious relationship between subjective life satisfaction and subjective self-reported satisfaction with current standard of living than between subjective life satisfaction and income itself. Moreover, there are differences between countries mainly due to income distribution.

We tested our assumptions by linear regression models calculated separately for Romania, the V4 and the EU-15. The values of regression coefficients confirmed that satisfaction with present standard of living had the highest positive effect on overall life satisfaction from all partial satisfaction elements. However, importance of this partial satisfaction was the weakest for citizens of the EU- 15 . In our analysis we have to take into consideration the process of the transformation from centrally planned to modern free market democracy and level of post-materialist value orientation of Romania and the V4 citizens. We can say that material living conditions are less important for the citizens of EU15 with more postmaterialist values. This finding is in accordance with Havasi (2013) who conducted multiple regression analyses that indicated differences between the EU countries in the magnitude of the effects of material conditions on subjective well-being. His findings confirm that this effect is smaller in the more postmaterialist countries. Despite the fact that Romania and the V4 have recorded obvious socio-economic progress, more than nine years after the EU accession we can say that they belong to the EU as less economic and social developed countries. These and many other factors can have an influence on value system of the citizens. According to Zagórski (2011), the post-modern period involves a process of decreasing importance of income and material living conditions in shaping life satisfaction. This does not mean that material conditions have become irrelevant; but their impact on happiness has decreased.

In spite of positive relationship between life satisfaction and income indicator, measure of life satisfaction cannot be considered as a reliable indicator of people's well-being, mainly because it does not sufficiently reflect objective circumstances of life. Even though there is a controversial debate about this relationship, Deaton (2008) argues that overall life satisfaction and partial life satisfaction elements are direct measures of the important aspects of human experience and therefore scientists and policy makers should better understand their meaning, relevance in the research and relationships between them and other objective measures (e.g. income, GDP per capita). Another important aspect which can affect life satisfaction is insecurity of future and fear of losing desired standard of living (Ekici and Koydemir, 2016). Some social groups (e.g. 
retired) can be more vulnerable than others (Eurofound, 2012). Therefore, deeper analysis of different social groups within countries can be useful.

Despite several limitations of our research (data from the third wave of EQOLS, restricted number of determinants of life satisfaction, absence of effects of financial crisis), we can say that material living conditions and satisfaction with current standard of living still play an important role in life satisfaction of citizens and the well-being of nations. Although material living conditions and economic development are important parts of social progress, new indicators have been recognized in accordance with the concept of sustainable development and respect for environmental limits (e.g. gross national happiness, happy planet index). Every process of economic growth should be explored also in terms of sustainability whether this growth is not injurious towards the public and the environment.

\section{REFERENCES}

Apparicio, P., Seguin, A.M. and Naud, D., 2008. The quality of the urban environment around public housing buildings in Montréal: An objective approach based on GIS and multivariate statistical analysis. Social Indicators Research, [e-journal] 86(3), pp.355-380. https://doi.org/10.1007/s11205-0079185-4.

Blanchflower, D.A. and Oswald, A.J., 2004. Well-being over time in Britain and the USA. Journal of Public Economics, [e-journal] 88, pp.1359-1386. https://doi.org/10.1016/S0047-2727(02)00168-8.

Cummins, R.A., 1998. The second approximation to an international standard of life satisfaction. Social Indicators Research, [e-journal] 43(3), pp.307-334. https://doi.org/10.1023/A:1006831107052.

Das, D., 2008. Urban quality of life: A case study of Guwahati. Social Indicators Research, 88(2), pp.297-310.

Deaton, A., 2008. Income, Health, and Well-Being around the World: Evidence from the Gallup World Poll. Journal of Economic Perspectives, [e-journal] 22(2), pp. 53-72. https://doi.org/10.1257/jep.22.2.53.

Diener, E. and Fujita, F., 1995. Resources, personal strivings, and subjective well-being: A nomothetic and idiographic approach. Journal of Personality and Social Psychology, 68(5), pp.926-935.

Diener, E., 2005. Guidelines for National Indicators of Subjective Well-Being and Ill-Being. Guidelines for National Indicators. [pdf] Illinois: University of Illinois. Available at: <http://internal.psychology.illinois.edu/ ediener/ Documents/Guidelines_for_National_Indicators.pdf $>$ [Accessed 10 June 2015]. 
Drule, A.-M., Popa, I. E., Nistor, R. and Chiş, A., 2014. Quality of the Teaching Process and its Factors of Influence from the Perspective of Future Business Specialists. Amfiteatru Economic, 16(37), pp.827-840.

Easterlin, R.A., 2013. Happiness and Economic Growth: The Evidence. Discussion Paper No. 7187. Bonn, Germany: IZA (The Institute for the Study of Labor). Available at: <http://ftp.iza.org/dp7187.pdf> [Accessed 7 March 2017].

Eby, J., Kitchen, P. and Williams, A., 2012. Perceptions of quality life in Hamilton's neighbourhood hubs: A qualitative analysis. Social Indicators Research, 108(2), pp.299-315.

Ekici, T. and Koydemir, S., 2016. Income Expectations and Happiness: Evidence from British Panel Data. Applied Research in Quality of Life, [e-journal] 11(2), pp.539-552. https://doi.org/10.1007/s11482-014-9380-9.

Eurofound (EQOLS), 2012. Third European Quality of Life Survey - Quality of life in Europe: Impacts of the crisis. [pdf] Luxembourg: Publications Office of the European Union. Available at: <http:/www.eurofound.europa.eu/sites/ default/files/ef_publication/field_ef_document/ef1264en_0.pdf $>$ [Accessed 12 September 2015].

Eurofound, 2015. European Quality of Life Surveys. [surveys > data-visualisation $>$ european-quality-of-life-survey-2012] EQLS [online]. Available through: $<$ http://www.eurofound.europa.eu/european-quality-of-life-surveys-eqls> [Accessed 15 March 2015].

Eurostat, 2011. Report of the Task Force: Multidimensional measurement of the quality of life. [pdf] Paris: INSEE. Available at: <http://ec.europa.eu/eurostat/ documents/42577/43503/TF3-Final-report-Quality-of-Life> [Accessed 15 May 2015].

Eurostat, 2015. European Survey on Income and Living Conditions. [Cross cutting topics $>$ Quality of life $>$ Material living conditions $>$ Income] EU-SILC [online]. Available through: <http://ec.europa.eu/eurostat/data/database> [Accessed 15 March 2015].

Fayers, P.M. and Machin, D., 2013. Quality of life. Assesment, analysis and interpretation of Patient Reported Outcomes. 2nd ed. Chichester: Wiley.

Frey, B.S. and Stutzer, A., 2001. Happiness \& economics. How the Economy and Institutions Affect Human Well-Being. Princeton: Princeton University Press.

Gavurová, B., 2012. Source Identification of Potential Malfunction of Balanced Scorecard System and Its Influence on System Function. E+M Ekonomie a management, 15(3), pp. 76-90.

Havasi, V., 2013. Financial Situation and Its Consequences on the Quality of Life in the EU Countries. Social Indicators Research, [e-journal] 113(1), pp.1735. https://doi.org/10.1007/s11205-011-9901-y. 
Inglehart, R. and Welzel, C., 2005. Modernization, cultural change, and democracy - the human development sequence. Cambridge: Cambridge University Press.

Inglehart, R., 1997. Modernization and postmodernization. Cultural, Economic and Political Change in 43 Societes. Princeton: Princeton University Press.

Khaef, S. and Zebardast, E., 2016. Assessing Quality of Life Dimensions in Deteriorated Inner Areas: A case from Javadieh Neighborhood in Tehran Metropolis. Social Indicators Research, [e-journal] 127(2), pp.761-775. https://doi.org/10.1007/s11205-015-0986-6.

Murgaš, F., 2009. Quality of life and its spatial differentiation in districts of Slovakia. Geografický časopis, 61, pp.121-138.

Řepková, I. and Stavárek, D., 2014. Concentration and Competition in the Banking Sector of Turkey. Amfiteatru Economic, 16(36), pp.625-640.

Royuela, V., Moreno, R. and Vayá, E., 2009. Influence of quality of life on urban growth: A case study of Barcelona, Spain. Regional Studies, [e-journal] 44(5), pp.551-567. https://doi.org/10.1080/00343400802662682.

Saksonova, S. and Vilerts, K., 2015. Measuring returns to education: The case of Latvia. Scientific Annals of the "Alexandru Ioan Cuza" University of Iaşi Economic Sciences, 62(2), pp.251-261.

Schyns, P., 2002. Wealth of nations, individual income and life satisfaction in 42 countries: A multilevel approach. Social Indicators Research, [e-journal] 60(5), pp.5-40. https://doi.org/10.1023/A:1021244511064.

Stiglitz, J.E., Sen, A. and Fitoussi, J.-P., 2009. Report of the commission on the measurement of economic performance at social progress. [pdf]. Available at: $<$ http://ec.europa.eu/eurostat/documents/118025/118123/Fitoussi+Commission+r eport> [Accessed 25 May 2015].

Ulengin, B., Ulengin, F. and Guvenc, U., 2001. A multidimensional approach to urban quality of life: The case of Istanbul. European Journal of Operational Research, [e-journal] 130(2), pp.361-374. https://doi.org/10.1016/S03772217(00)00047-3.

Veenhoven, R., 1996. Happy Life-expectancy: A comprehensive measure of quality-of-life in nations. Social Indicators Research, 39, pp.1-58.

Veenhoven, R., 2005. Apparent quality-of-life in nations: How long and happy people live. Social Indicators Research, [e-journal] 71(1-3), pp.61-86. https://doi.org/10.1007/s11205-004-8014-2.

Wiese, T.R., 2014. The cyclical component of GDP and life satisfaction: The impact of the Mediterranean welfare system. Society and Economy, 36(4), pp.529-542. https://doi.org/10.1556/SocEc.36.2014.4.5. 
Zagórski, K., 2011. Income and Happiness in Time of Post-Communist Modernization. Social Indicators Research, [e-journal] 104(2), pp.331-349. https://doi.org/10.1007/s11205-010-9749-6.

Zagórski, K., Kelley, J. and Evans, M.D.R., 2010. Economic development and happiness: Evidence from 32 nations. Polish Sociological Review, 1(169), pp.319.

\section{ABOUT AUTHORS}

Vincent Šoltés is a professor of Finance at Department of Finance, Faculty of Economics, Technical University of Košice, Slovakia, e-mail: vincent.soltes@tuke.sk.

Bibiána Nováková is a $\mathrm{PhD}$ student at the Faculty of Economics, Technical University of Košice, Slovakia, e-mail: bibiana.novakova@tuke.sk.

Zsuzsanna Katalin Szabo is professor at Management-Economy Department at Petru Maior University of Tîrgu Mures, Romania. e-mail: szabo.zs.katalin@gmail.com. 